\title{
Transcatheter valve implantation for degenerated tricuspid bioprosthesis and failed tricuspid ring
}

\author{
Shmuel Chen, Lyle Dershowitz, Isaac George \\ Division of Cardiac, Thoracic \& Vascular Surgery, Columbia University Irving Medical Center/NewYork-Presbyterian Hospital, New York, NY, \\ USA \\ Correspondence to: Isaac George, MD. Division of Cardiac, Thoracic \& Vascular Surgery, New York Presbyterian Hospital - Columbia University \\ Medical Center, Milstein 7GN-435, 177 Fort Washington Ave, New York, NY 10032, USA. Email: ig2006@cumc.columbia.edu.
}

\begin{abstract}
Background: Transcatheter tricuspid valve-in-valve (TViV) and valve in-ring (TViR) implantation have become a viable therapy for a failed tricuspid bioprosthesis. Here we report short (thirty days) and long (oneyear) term clinical outcomes of ten patients who underwent TViV at our institution.

Methods: The electronic databases of New York Presbyterian Columbia Medical Center were retrospectively reviewed for cases of transcatheter tricuspid valve replacement (TViV or TViR). Between 2012 and 2019, data from ten patients who underwent TViV were collected. The primary safety outcome was procedure-related adverse events, including clinically evident cardiac perforation, new pericardial effusion and sustained ventricular arrhythmia. The primary efficacy endpoint was defined as successful valve deployment with total (paravalvular or intravalvular) tricuspid regurgitation (TR) estimated as mild or less. Results are descriptive in nature.

Results: A total of ten patients who underwent TViV were included in the study. Of them, $40 \%$ presented with isolated tricuspid bioprosthetic stenosis (TS), 20\% with isolated TR and 40\% with mixed TS and TR. All patients were treated with the SAPIEN valve (first generation, XT, or Sapien 3). The TViV procedure was successful in all patients, and no immediate post-replacement paravalvular leak (PVL) or intra-procedural complications were reported. The primary safety and efficacy endpoints were met in all patients. At thirtydays, all patients were alive and reported significant improvements in symptoms and functional status.

Conclusions: Transcatheter tricuspid valve implantation is a safe and effective therapy for degenerative tricuspid bioprosthesis.
\end{abstract}

Keywords: Transcatheter tricuspid valve replacement; valve in valve; valve in ring

Submitted Mar 22, 2021. Accepted for publication Jul 29, 2021.

doi: 10.21037/acs-2021-tviv-11

View this article at: https://dx.doi.org/10.21037/acs-2021-tviv-11

\section{Introduction}

Biological prostheses in the tricuspid position are at risk of degeneration, resulting in prosthesis failure, manifesting as tricuspid regurgitation (TR) or stenosis (TS). An accurate rate of tricuspid valve replacement (TVR) longevity is difficult to estimate because data available for 'freedom from reoperation' likely underestimates the true incidence of valve degeneration, since reoperation for isolated tricuspid valve (TV) disease is rare and carries a high degree of surgical risk (1). The reported bioprosthesis failure (TR or TS) rate necessitating re-operation is between $10 \%$ and
$22 \%$ during a follow-up of five to nine years (2-6). These rates are even higher for patients with Ebstein's anomaly, with a reoperation rate of $18-26 \%$ within ten years $(2,7,8)$.

Surgical replacement of failing tricuspid prosthesis is among the highest risk operations classified in the Society of Thoracic Surgeons (STS) registry, particularly in the presence of right ventricular dysfunction (9). Thus, transcatheter tricuspid valve-in-valve (TViV) and valve-inring (TViR) implantation have become a viable therapy for a failed tricuspid bioprosthesis (10), due to the favorable safety profile and high success rate of $\mathrm{TViV}$ and $\mathrm{TViR}$ compared 


\begin{tabular}{|c|c|c|c|c|c|c|c|c|c|c|}
\hline 1 & 79 & M & 23 & 8 & Valve & Carpentier-Edwards & 25 & Severe TS & 6 & $n / a$ \\
\hline 2 & 58 & $\mathrm{~F}$ & 8.9 & 4.7 & Valve & "Tissue" & 33 & Severe TR, Severe TS & 7 & 0.3 \\
\hline 4 & 31 & M & 1.0 & 9.3 & Valve & Carpentier-Edwards & 33 & Severe TS, Moderate TR & 4 & 0.5 \\
\hline 5 & 70 & $\mathrm{~F}$ & 29.9 & 5.9 & Valve & Carpentier-Edwards & 33 & Severe TS & 6.3 & $\mathrm{n} / \mathrm{a}$ \\
\hline 6 & 28 & M & 1.8 & 5.2 & Valve & EPIC & 33 & Severe TR & 6.5 & $\mathrm{n} / \mathrm{a}$ \\
\hline 7 & 59 & M & 11.3 & 12.2 & Valve & Carpentier-Edwards & 33 & Severe TS & 14 & 0.3 \\
\hline 10 & 40 & $\mathrm{~F}$ & 1.8 & 10.5 & Valve & Edwards 6900 & 33 & Severe TR & 2.5 & 0.9 \\
\hline
\end{tabular}

TS, tricuspid stenosis; TR, tricuspid regurgitation; LEE, lower extremity edema; DOE, dyspnea on exertion; STS, Society of Thoracic Surgeons; TVR, tricuspid valve replacement; iEOA, index effective orifice area.

with redo tricuspid surgery (11). This is especially apparent in the setting of right ventricular dysfunction, which is frequently associated with a failed tricuspid prosthesis and inversely influences surgical outcomes (12-15).

\section{Methods}

\section{Patients and data collection}

The electronic databases of New York Presbyterian Columbia Medical Center were retrospectively reviewed for cases of transcatheter tricuspid valve replacement ( $\mathrm{TViV}$ or TViR). From June 2012 to November 2019, data was retrospectively collected from ten consecutive patients treated with transcatheter tricuspid valve replacement. All procedures were performed at Columbia University Medical Center, New York, NY. Patient data was obtained through retrospective record review. Thirty-day events were acquired from the office visit record.

\section{Endpoints}

The primary safety endpoint was procedure-related adverse events, including clinically evident cardiac perforation, new pericardial effusion and sustained ventricular arrhythmia. The primary efficacy endpoint was defined as successful valve deployment with total (paravalvular or intravalvular) tricuspid regurgitation estimated as mild or less.

\section{Statistical analysis}

Results are depicted as median [interquartile range (IQR)] for numerical data and percentage for categorical data. Results are descriptive in nature.

\section{Results}

\section{Demographic data}

A total of ten patients with degenerated tricuspid bioprosthetic valve were included in this study. Baseline characteristics are presented in Tables 1,2 and Tables S1S3. All patients had a significant comorbidity burden with median STS score of 9.5\% (IQR 1.8, 19.3) and significant exertional limitations, with $70 \%$ of patients with greater than or equal to NYHA class 3 symptoms. Other heart failure symptoms were edema $(70 \%)$, ascites $(40 \%)$, and fatigue $70 \%)$. Of the ten patients, $40 \%$ presented with isolated TS, $20 \%$ with isolated TR, and $40 \%$ with mixed TS and TR.

\section{Procedural outcomes}

All patients were treated with the SAPIEN transcatheter heart valve (THV) (first generation, XT or Sapien 3; Table 3) 
Table 2 Clinical and echocardiographic characteristics at baseline

\begin{tabular}{|c|c|c|c|c|c|c|c|c|c|c|c|}
\hline Patient & $\begin{array}{l}\text { LE } \\
\text { edema }\end{array}$ & $\begin{array}{l}\text { Ascites } \\
\text { (abdominal } \\
\text { distention) }\end{array}$ & Fatigue & $\begin{array}{l}\text { Pleural } \\
\text { effusion }\end{array}$ & NYHA & LVEF$^{*}$ & LV size* & $\mathrm{RVF}^{*}$ & RV size* & RVSP* & $\begin{array}{l}\mathrm{TR}^{\star} \\
\text { (central/PVL) }\end{array}$ \\
\hline 2 & - & - & + & - & 2 & 68 & Normal & Normal & Normal & $\mathrm{n} / \mathrm{a}$ & Severe central \\
\hline 3 & + & - & + & - & 2 & $60-65$ & Normal & Normal & Normal & 38 & Moderate central \\
\hline 5 & + & + & + & + & 4 & $55-60$ & Small cavity & Preserved & Normal & 33 & Mild central \\
\hline 6 & - & - & + & - & 4 & $10-15$ & Small cavity & Severely reduced & $\begin{array}{l}\text { Severely } \\
\text { increased }\end{array}$ & $\mathrm{n} / \mathrm{a}$ & Severe central \\
\hline 9 & + & - & - & - & 3 & $60-65$ & Normal & Normal & Normal & $\mathrm{n} / \mathrm{a}$ & Mild central \\
\hline 10 & + & - & - & - & 3 & 71 & Normal & $\begin{array}{l}\text { Moderately-severely } \\
\text { reduced }\end{array}$ & $\begin{array}{l}\text { Severely } \\
\text { increased }\end{array}$ & 31 & Severe central \\
\hline
\end{tabular}

LE, lower extremity; NYHA, New York Heart Association; LVEF, left ventricular ejection fraction; LV, left ventricle; RVF, right ventricular function; RV, right ventricle; RVSP, right ventricular systolic pressure; TR, tricuspid regurgitation.

Table 3 Procedure outcomes

\begin{tabular}{|c|c|c|c|c|c|c|c|}
\hline Patient & THV brand & THV Size & $\begin{array}{l}\text { iEOA (immediate post) } \\
\left(\mathrm{cm}^{2} / \mathrm{m}^{2}\right)\end{array}$ & $\begin{array}{l}\text { PVL grade } \\
\text { (immediate post) }\end{array}$ & $\begin{array}{l}\text { Mean gradient } \\
(\mathrm{mmHg})\end{array}$ & $\begin{array}{l}\text { Procedure } \\
\text { complications }\end{array}$ & $\begin{array}{l}\text { Length of } \\
\text { hospitalization }\end{array}$ \\
\hline 1 & Sapien & 26 & 1.4 & None & 2 & None & 4 \\
\hline 2 & Sapien XT & 29 & 1.1 & None & 2 & None & 1 \\
\hline 3 & Sapien XT & 29 & 1.7 & None & 1 & None & 1 \\
\hline 4 & Sapien XT & 29 & 1.3 & None & 1 & None & 3 \\
\hline 5 & Sapien 3 & 29 & 1.4 & None & 1 & None & 23 \\
\hline 6 & Sapien 3 & 29 & $\mathrm{n} / \mathrm{a}$ & None & 1.7 & None & 1 \\
\hline 7 & Sapien 3 Ultra Valve & 29 & 1.2 & None & 2 & None & 29 \\
\hline 8 & Sapien 3 & 29 & $\mathrm{n} / \mathrm{a}$ & None & 4.8 & None & 6 \\
\hline 9 & Sapien 3 & 29 & $\mathrm{n} / \mathrm{a}$ & None & 4 & None & 2 \\
\hline 10 & Sapien 3 Ultra Valve & 29 & 1.3 & None & 2 & None & 1 \\
\hline
\end{tabular}




\begin{tabular}{|c|c|c|c|c|c|c|c|c|c|c|c|}
\hline 1 & + & + & + & + & 3 & 55 & Normal & $\begin{array}{l}\text { Mildly } \\
\text { reduced }\end{array}$ & $\begin{array}{l}\text { Mildly } \\
\text { increased }\end{array}$ & $\mathrm{n} / \mathrm{a}$ & None \\
\hline 3 & - & - & - & - & $\begin{array}{l}\text { "Exercise tolerance has } \\
\text { definitely improved" }\end{array}$ & $60-65$ & Normal & Normal & Normal & $n / a$ & $\begin{array}{l}\text { Trace } \\
\text { central }\end{array}$ \\
\hline 4 & - & - & - & - & $\begin{array}{l}\text { "Improvement in } \\
\text { stamina" }\end{array}$ & 60 & $\begin{array}{l}\text { Mildly } \\
\text { reduced }\end{array}$ & $\begin{array}{l}\text { Severely } \\
\text { reduced }\end{array}$ & $\begin{array}{l}\text { Severely } \\
\text { increased }\end{array}$ & 25 & $\begin{array}{l}\text { Trace } \\
\text { central }\end{array}$ \\
\hline 5 & - & - & + & + & $\begin{array}{l}\text { "Feeling better but still } \\
\text { limited due to DOE" }\end{array}$ & $\mathrm{n} / \mathrm{a}$ & $\mathrm{n} / \mathrm{a}$ & $\mathrm{n} / \mathrm{a}$ & $\mathrm{n} / \mathrm{a}$ & $\mathrm{n} / \mathrm{a}$ & $\mathrm{n} / \mathrm{a}$ \\
\hline 7 & + & - & - & - & $\begin{array}{l}\text { "DOE is much } \\
\text { improved" }\end{array}$ & $\begin{array}{l}65 \text { (2 weeks } \\
\text { post) }\end{array}$ & Normal & $\begin{array}{l}\text { Severely } \\
\text { reduced }\end{array}$ & $\begin{array}{l}\text { Mildly } \\
\text { increased }\end{array}$ & $\mathrm{n} / \mathrm{a}$ & Trace PVL \\
\hline 8 & - & - & - & - & 2 & 50-55 & $\begin{array}{l}\text { Mildly } \\
\text { increased }\end{array}$ & $\begin{array}{l}\text { Borderline } \\
\text { reduced }\end{array}$ & Normal & $n / a$ & None \\
\hline 9 & + & - & - & - & 2 & $\mathrm{n} / \mathrm{a}$ & $\mathrm{n} / \mathrm{a}$ & $n / a$ & $\mathrm{n} / \mathrm{a}$ & $\mathrm{n} / \mathrm{a}$ & $n / a$ \\
\hline 10 & - & - & - & - & 2 & $\mathrm{n} / \mathrm{a}$ & $\mathrm{n} / \mathrm{a}$ & $\mathrm{n} / \mathrm{a}$ & $\mathrm{n} / \mathrm{a}$ & $\mathrm{n} / \mathrm{a}$ & $n / a$ \\
\hline
\end{tabular}

(Edwards Lifesciences, Irinve, California, USA). The TViV procedure was successful in all patients, and no immediate post-replacement paravalvular leak (PVL) was reported in any patient. All patients tolerated the procedure well, and no intra-procedural complications were reported. No patient required treatment with inotropes or mechanical support after the procedure. Median length of hospitalization was 2.5 days (IQR 1,6 ), and the majority of patients $(90 \%)$ were treated with anticoagulation at discharge (of them, three patients were treated with anticoagulation on admission).

\section{Thirty-day outcomes}

At thirty-days, all patients were alive and reported significant improvements in symptoms and functional status (Table 4). Edema improved in four patients (40\%), ascites in three patients $(30 \%)$ and follow-up echocardiography at a median of 1.3 months (IQR 0.7, 4.2) confirmed the absence of significant residual TR in all patients. Left ventricular
(LV) function remained similar to baseline in all patients. Right ventricular (RV) function remained stable at thirtydays after the procedure in two patients, deteriorated in three patients and improved in one patient. Treatment with diuretics at thirty-days remained similar to baseline (preprocedure).

\section{Discussion}

In the current study, we evaluated the safety and efficacy of $\mathrm{TViV}$ in a single center registry. In this study, the TViV provided an effective and safe alternative to surgery in patients with high to prohibitive surgical risk. Our findings are in line with previously published data from 306 patients who underwent transcatheter tricuspid valve replacement (TViV or TViR) (10), demonstrating the feasibility and safety of the procedure. In the current study, all patients reported significant clinical improvement. Follow-up echocardiography confirmed the absence of significant TR 

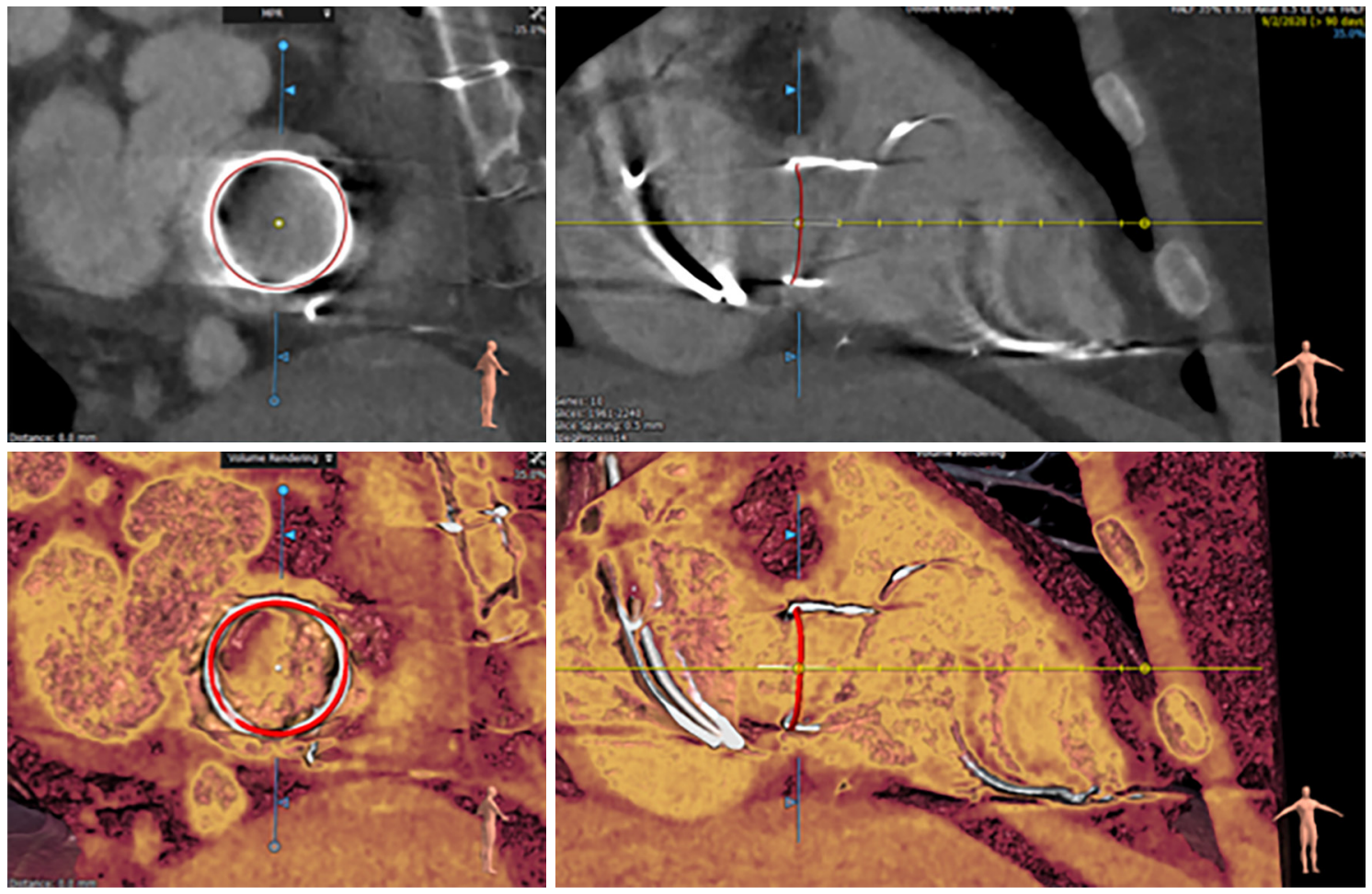

Figure 1 Computed tomography reconstruction of the tricuspid valve annulus. Valve sizing can be performed using the surgical sewing ring inner and outer dimensions.

(central or paravalvular) in all patients.

\section{Transcatheter valve sizing}

The planning of a TViV or TViR procedure includes the identification of the surgical prosthesis and transcatheter valve size. For TViV, examination of the surgical implant information (prosthesis card or surgical note) and multimodality imaging are used in order to determine the true internal diameter of the surgical prosthesis, to enable an accurate THV sizing. For this purpose, computed tomography (CT) imaging should be performed in all cases (Figure 1), if kidney function allows, particularly in TViR, or in cases where the surgical valve size is unknown. Alternatively, particularly in patients with kidney dysfunction, transesophageal echocardiography (TEE) should be performed. Both modalities (CT and TEE) also provide additional important information, such as the presence of PVL, prosthesis thrombus or infective endocarditis, as these are exclusion criteria for transcatheter $\mathrm{TViV}$ or TViR. Due to the presence of the mounted leaflets inside the valve prosthesis, the true internal diameter is typically 1 to $2 \mathrm{~mm}$ smaller than the diameter of the surgical valve prosthesis size reported by the manufacturer (16). As there are no dedicated surgical bioprostheses for the tricuspid position, the mitral Valve-in-Valve app (17) can be used to identify the surgical prosthesis type and guide THV size selection and positioning. If a Melody valve (Medtronic PLC, Minneapolis, Minnesota) is implanted, balloon sizing of the existing bioprosthesis is usually performed to profile the waist of the existing bioprosthesis (18). In the case of TViR, CT and balloon-sizing are useful in THV sizing.

\section{Transcatheter valve selection}

Valve selection is guided by the patient's anatomy and the size of the surgical prosthesis. In general, the Melody valve is preferable for a surgical bioprosthesis with an inner diameter of $\leq 23 \mathrm{~mm}$ (Melody valve inner diameter $22 \mathrm{~mm}$, outer diameter $24 \mathrm{~mm}$ ), and the Edwards SAPIEN 3 valve for a surgical bioprosthesis with an inner diameter of $\geq 29 \mathrm{~mm}$ (SAPIEN 3 valve is available in sizes up to $29 \mathrm{~mm}$, which can be over-expanded up to $31 \mathrm{~mm}$ ) (18). For a surgical bioprosthesis with an outer diameter between 
25 and $29 \mathrm{~mm}$, both THVs can be used. While the Melody valve is mounted in the standard fashion, a SAPIEN 3 valve must be mounted for antegrade delivery onto the delivery catheter, and the valve delivery system introduced with the Edwards ' $E$ ' logo facing downward, in order to allow for appropriate flexion of the catheter.

\section{Transcatheter valve positioning and implantation}

The procedure is performed under fluoroscopy and echocardiography guidance [transthoracic echocardiography (TTE) or TEE]; both moderate sedation and general anesthesia can be used, depending on patient-related risk factors. The procedure can be performed via a transfemoral or a transjugular route. However, transfemoral access has become the most frequently used route with the development of more directable and flexible valve delivery systems, which have allowed for operators to overcome the acute angle between the inferior vena cava and the tricuspid valve. After obtaining femoral vein access with a five French sheath system, pre-close is typically performed with one Perclose ProGlide suture-mediated closure system. The sheath is then replaced with a dedicated large sheath (14-16 French) and the tricuspid valve is crossed with a straight-tip wire (stiff glidewire for TS or tiger-wire for TR). This wire is replaced with a pre-formed stiff wire which is positioned through the surgical bioprosthesis at the RV apex. Special attention should be paid to confirm that the stiff wire is crossing within the bioprosthesis rather than through a PVL. The selected THV is advanced to the deployment position: for surgical prostheses with a visible stent frame, the central marker of the SAPIEN 3 valve should be aligned $3 \mathrm{~mm}$ ventricular to the atrial edge of surgical bioprosthesis stent frame, while for surgical valves with visible outflow markers, the outflow of the crimped SAPIEN 3 valve should be aligned 1-2 $\mathrm{mm}$ atrial to the ventricular surgical valve outflow markers. For surgical valves with no radiopaque markers, the base of the central SAPIEN 3 marker should be aligned with the annular plane. A sample video is shown (Video 1). The Melody valve is typically implanted with about $40 \%$ of the stent frame on the atrial side (18). The primary principle for deployment is: (I) anchor the transcatheter valve at the sewing ring of the surgical, and (II) land the THV such that leaflet overhang of the surgical prosthesis does not occur. The foreshortening of the SAPIEN 3 valve frame occurs from the inflow, corresponding to the right atrial side of the valve.

In cases of TViR implantation, it is important to determine whether the prosthesis is a ring or a band, complete or incomplete and flexible, rigid or semirigid. Compared with rigid or semirigid bands and complete rings, flexible bands are more challenging for THV anchoring, as they may expand during THV deployment. In fact, flexible bands convey the highest risk for THV embolization, which should be taken into consideration before performing TViR in such prostheses. On the other hand, the flexible bands have a lower risk of paravalvular leak, as semi-rigid and rigid rings will not circularize. The resulting PVL can be severe and/or require PVL closure. In the case of TViR, the central marker of the SAPIEN 3 prosthesis should be aligned $2 \mathrm{~mm}$ ventricular to the annular ring. Caution should be undertaken before proceeding with any $\mathrm{TViR}$, due to the much higher risks and lower chance of procedural success.

Once the THV is positioned appropriately across the surgical prosthesis, it should be deployed in a slow and controlled fashion to allow for adjustment of the THV position as needed. In most cases THV deployment can be performed without pacing. In cases of excessive cardiac motion, pacing can be performed in the coronary sinus, or through the stiff wire located in the RV apex. In the case of a pre-existing permanent pacemaker, jailing of its leads by the THV is usually well tolerated, and does not cause significant PVL. Close coordination between the two implanters and a slow deployment, with continuous adjustment, is required for accurate positioning. Additional guidance for deployment can be found on the VIV app.

\section{Limitations}

The current study intends to describe our primary experience with TViV and includes a small number of patients. All transcatheter valve implantations were performed for degenerative tricuspid bioprosthesis and none were performed for failed tricuspid ring. In addition, patients were carefully selected and approved by a local heart team. As such, the results presented above cannot be generalized to all patients with surgical prosthesis failure and should be carefully interpreted. Follow up is limited to 30 days and long term follow up and data regarding the longevity of TViV are not available. Nevertheless, data presented above support previous reports that in selected patients with surgical prosthesis failure, $\mathrm{TViV}$ or $\mathrm{TViR}$ is a feasible and safe procedure. The THV durability and longterm clinical outcomes are still unknown, as are the risk for leaflet thrombosis and endocarditis. Accordingly, the 
optimal medical treatment regimen after $\mathrm{TViV}$ or $\mathrm{TViR}$ (aspirin, dual anti-platelets, or anticoagulation) is yet to be determined.

\section{Acknowledgments}

Funding: None.

\section{Footnote}

Conflicts of Interest: IG: CardioMech, VDyne, Atricure, ValCare Medical, MitreMedical, J\&J. SC and LD: none.

Open Access Statement: This is an Open Access article distributed in accordance with the Creative Commons Attribution-NonCommercial-NoDerivs 4.0 International License (CC BY-NC-ND 4.0), which permits the noncommercial replication and distribution of the article with the strict proviso that no changes or edits are made and the original work is properly cited (including links to both the formal publication through the relevant DOI and the license). See: https://creativecommons.org/licenses/by-nc-nd/4.0/.

\section{References}

1. Krishnaswamy A, Navia J, Kapadia SR. Transcatheter Tricuspid Valve Replacement. Interv Cardiol Clin 2018;7:65-70.

2. van Slooten YJ, Freling HG, van Melle JP, et al. Longterm tricuspid valve prosthesis-related complications in patients with congenital heart disease. Eur J Cardiothorac Surg 2014;45:83-9.

3. Hwang HY, Kim KH, Kim KB, et al. Mechanical tricuspid valve replacement is not superior in patients younger than 65 years who need long-term anticoagulation. Ann Thorac Surg 2012;93:1154-60.

4. Garatti A, Nano G, Bruschi G, et al. Twenty-five year outcomes of tricuspid valve replacement comparing mechanical and biologic prostheses. Ann Thorac Surg 2012;93:1146-53.

5. Filsoufi F, Anyanwu AC, Salzberg SP, et al. Long-term outcomes of tricuspid valve replacement in the current era. Ann Thorac Surg 2005;80:845-50.

6. Van Nooten GJ, Caes F, Taeymans Y, et al. Tricuspid valve replacement: postoperative and long-term results. J Thorac Cardiovasc Surg 1995;110:672-9.

7. Brown ML, Dearani JA, Danielson GK, et al. Comparison of the outcome of porcine bioprosthetic versus mechanical prosthetic replacement of the tricuspid valve in the Ebstein anomaly. Am J Cardiol 2009;103:555-61.

8. Kiziltan HT, Theodoro DA, Warnes CA, et al. Late results of bioprosthetic tricuspid valve replacement in Ebstein's anomaly. Ann Thorac Surg 1998;66:1539-45.

9. Kilic A, Saha-Chaudhuri P, Rankin JS, et al. Trends and outcomes of tricuspid valve surgery in North America: an analysis of more than 50,000 patients from the Society of Thoracic Surgeons database. Ann Thorac Surg 2013;96:1546-52; discussion 1552.

10. McElhinney DB, Aboulhosn JA, Dvir D, et al. Mid-Term Valve-Related Outcomes After Transcatheter Tricuspid Valve-in-Valve or Valve-in-Ring Replacement. J Am Coll Cardiol 2019;73:148-57.

11. Bernal JM, Morales D, Revuelta C, et al. Reoperations after tricuspid valve repair. J Thorac Cardiovasc Surg 2005;130:498-503.

12. Taggart NW, Cabalka AK, Eicken A, et al. Outcomes of Transcatheter Tricuspid Valve-in-Valve Implantation in Patients With Ebstein Anomaly. Am J Cardiol 2018;121:262-8.

13. Onorati F, Perrotti A, Reichart D, et al. Surgical factors and complications affecting hospital outcome in redo mitral surgery: insights from a multicentre experience. Eur J Cardiothorac Surg 2016;49:e127-33.

14. Rogers JH, Bolling SF. The tricuspid valve: current perspective and evolving management of tricuspid regurgitation. Circulation 2009;119:2718-25.

15. Avcin M. Effect of physical culture on growth and development of children. Med Glas 1950;4:107-9.

16. Praz F, George I, Kodali S, et al. Transcatheter Tricuspid Valve-in-Valve Intervention for Degenerative Bioprosthetic Tricuspid Valve Disease. J Am Soc Echocardiogr 2018;31:491-504.

17. Bapat V. Valve-in-valve apps: why and how they were developed and how to use them. EuroIntervention 2014;10 Suppl U:U44-51.

18. Sanon S, Cabalka AK, Babaliaros V, et al. Transcatheter Tricuspid Valve-in-Valve and Valve-in-Ring Implantation for Degenerated Surgical Prosthesis. JACC Cardiovasc Interv 2019;12:1403-12.

Cite this article as: Chen S, Dershowitz L, George I. Transcatheter valve implantation for degenerated tricuspid bioprosthesis and failed tricuspid ring. Ann Cardiothorac Surg 2021;10(5):651-657. doi: 10.21037/acs-2021-tviv-11 


\section{Supplementary}

Table S1 Further clinical and laboratory data at baseline and $30 \mathrm{~d}$ post-procedure

\begin{tabular}{|c|c|c|c|c|c|c|c|c|c|c|}
\hline Patients & \multicolumn{2}{|c|}{ Weight (kg) } & \multicolumn{2}{|c|}{ Creatinine } & \multicolumn{2}{|l|}{ Albumin } & \multicolumn{2}{|l|}{ Pro-BNP } & \multicolumn{2}{|l|}{ Diuretics/Dose } \\
\hline 1 & 76.8 & 76.1 & 2.2 & 1.9 & 3 & 2.7 & 386.8 & $\mathrm{n} / \mathrm{a}$ & Furosemide 40mg BID & $\begin{array}{l}\text { Bumetanide } 1 \mathrm{mg} \text { po bid, } \\
\text { Metolazone } 5 \mathrm{mg} \text { PRN }\end{array}$ \\
\hline 2 & 59.1 & 61.7 & 0.7 & $\mathrm{n} / \mathrm{a}$ & 3.6 & $\mathrm{n} / \mathrm{a}$ & $\mathrm{n} / \mathrm{a}$ & $\mathrm{n} / \mathrm{a}$ & None & None \\
\hline 3 & 51.8 & 50 & 0.8 & $\mathrm{n} / \mathrm{a}$ & 4.1 & $\mathrm{n} / \mathrm{a}$ & $\mathrm{n} / \mathrm{a}$ & $\mathrm{n} / \mathrm{a}$ & None & None \\
\hline 5 & 58.5 & 48.5 & 3.1 & 2.92 & 3.4 & 3.9 & 9719 & $\mathrm{n} / \mathrm{a}$ & Furosemide 20mg TID & Torsemide $20 \mathrm{mg}$ qd \\
\hline 6 & 62 & 58.9 & 0.9 & $\mathrm{n} / \mathrm{a}$ & 5 & $\mathrm{n} / \mathrm{a}$ & 1534 & $\mathrm{n} / \mathrm{a}$ & None & None \\
\hline 7 & 82.2 & 66.2 & 1.3 & 1.1 & 3 & 4.1 & 1008 & 940 & Furosemide $40 \mathrm{mg}$ qd & Furosemide $80 \mathrm{mg}$ BID \\
\hline
\end{tabular}

BNP, B-type natriuretic peptide; d, days; BID, twice daily; PRN, as needed; po, oral; mg, milligram; qd, once daily; tid, three times daily; $\mathrm{kg}$, kilograms.

Table S2 Antiplatelet and anticoagulation therapy at discharge

\begin{tabular}{|c|c|c|c|}
\hline Patient & \multicolumn{3}{|c|}{ Medical therapy at discharge } \\
\hline 1 & $81 \mathrm{mg}$ qd & $\mathrm{n} / \mathrm{a}$ & Coumadin $2.5 \mathrm{mg}$ qd \\
\hline 2 & $81 \mathrm{mg}$ qd & Plavix 75 mg qd & $\mathrm{n} / \mathrm{a}$ \\
\hline 3 & $81 \mathrm{mg}$ qd & $\mathrm{n} / \mathrm{a}$ & Coumadin $5 \mathrm{mg}$ qd \\
\hline 5 & $\mathrm{n} / \mathrm{a}$ & $\mathrm{n} / \mathrm{a}$ & Coumadin $5 \mathrm{mg}$ qd \\
\hline 6 & $\mathrm{n} / \mathrm{a}$ & $\mathrm{n} / \mathrm{a}$ & Xarelto $20 \mathrm{mg}$ qd \\
\hline 7 & $\mathrm{n} / \mathrm{a}$ & $\mathrm{n} / \mathrm{a}$ & Coumadin 2 mg qd \\
\hline 8 & $81 \mathrm{mg} \mathrm{qd}$ & $\mathrm{n} / \mathrm{a}$ & Coumadin $1 \mathrm{mg}$ tid \\
\hline
\end{tabular}




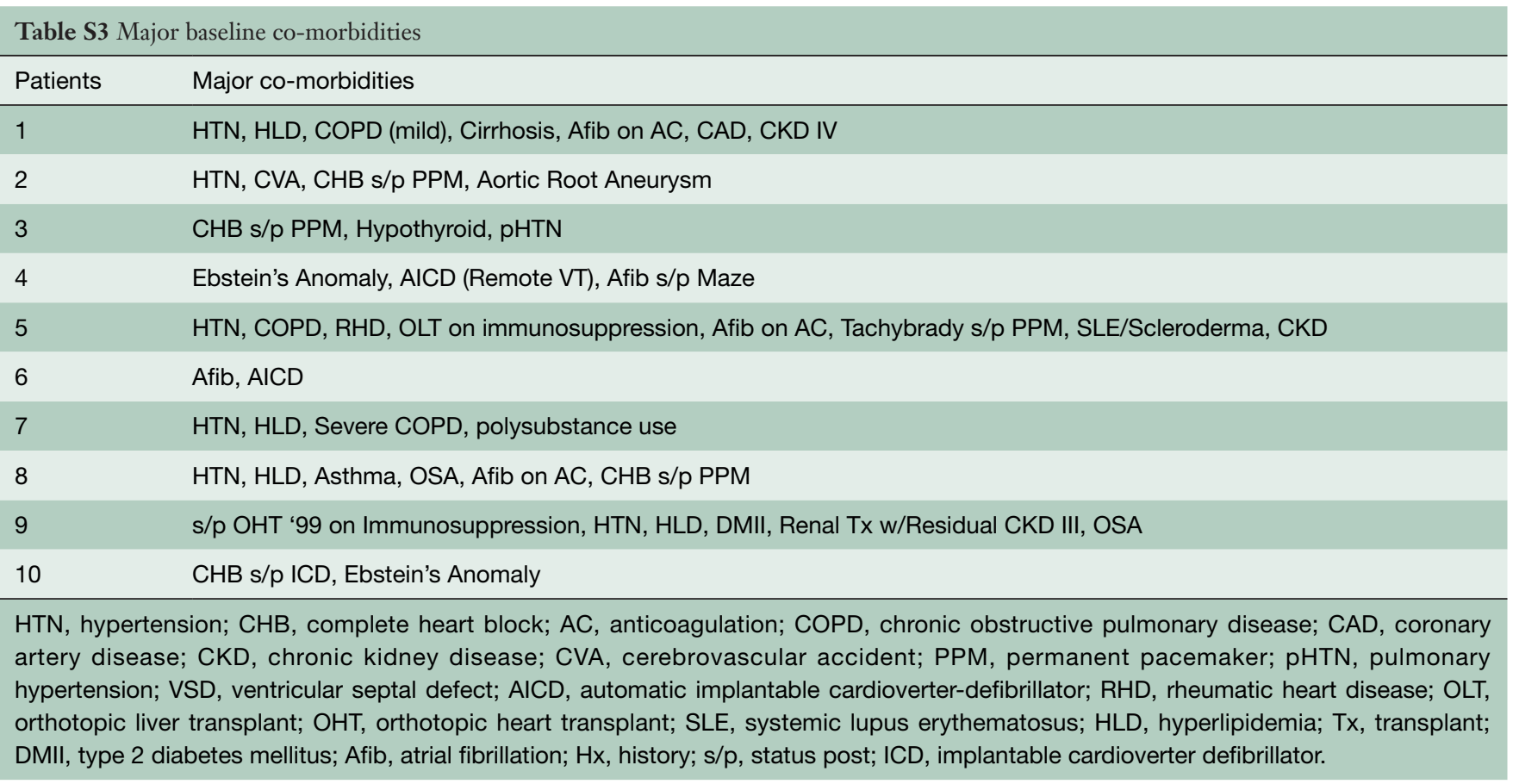

